\title{
correspondence
}

\section{Earthquake risk}

Sir,-The succession of devastating earthquakes in recent months has vividly borne out O'Keefe et al's conclusion" that "natural" disasters are on the increase. More remains to be learned about precursory phenomena before earthquakes can be forecast reliably enough to save lives regularly. Yet much can be done in other ways to mitigate the hazards. Earthquake risk is highest where the probability of earthquake occurrence and the vulnerability of an area combine to maximum effect, and in practical terms it is this that requires quantitative evaluation. Molchan et $a l^{2}$ have developed a mathematical analysis of earthquake risk but whereas evaluation of earthquake occurrence has attracted considerable attention, through compilation of seismic zoning maps and so on, the evaluation of vulnerability has received much less. Vulnerability is the distribution of loss potential, measured in financial terms, and is given by the actuarial assessment of the damage potential in an area both of material losses and social losses (loss of life, injury, loss of work, family, social disruption).

Planning must attempt to reduce vulnerability in areas of high seismicity, but it would be impracticable to design for total invulnerability. Hence, a measure of degree of vulnerability is needed. Engineers use the concept of earthquake resistance in structural design. I propose a similar concept of earthquake resilience should be used in the same way to assess the social and economic response. Just as engineers accept that some degree of damage to structures in an earthquake must be tolerated, so it must be accepted that some social losses have to be faced. Certain essential services such as hospitals, and fire fighting units may need special protection, both in terms of buildings and personnel. But other structures and services may perhaps be disrupted without long term detriment to the society. The concept of resilience provides a means of estimating the power of recovery of society in the event of an earthquake. With this methodology, the balance can be worked out for an acceptable expenditure to provide a tolerable degree of protection against an earthquake, which can be afforded within the economy of the country as a whole and which forms an integral part of its national development plan.

\section{J. Blundell}

Department of Geology,

Chelsea College,

University of London, UK

I O'Keefe, P., Westgate. K. and Wisner, B. "Taking the naturalness out of natural disasters," Nature, 260, 566-567 (1976).

2 Molchan, G. M.. Keilis-Borok, V. I., and Vilkovich G. S." "Seismicity and principal seismic effects," Geophys. J. R. astr. Soc., 21, 323-335 (1970).

\section{Significant journals of science}

SIR,-The review article of Garfield (December 16, 1976, pages 609-615) contains relevant information in Table 3 , where the impact factor (that is, the rat:o between the citations in the 1974 Science Citation Index and articles published) of scientific journals is being presented in three specialities. Tables 1 and 2 , on the other hand, are misleading. The ranking is by total number of citations. This criterion is invalid for a cross-section of all scientific journals.

In a field, say general medicine, where as a matter of example 10,000 workers each publish a paper with on average 10 references, this means 100,000 citations; material science, with 100 investigators and the same ratio, would yield only 1,000 citations. Thus the total number of citations, and in some lesser measure the "impact" too, are influenced by the total number of people interested in a given speciality.

Of the many factors influencing the number of laboratories working in any given field (besides fashion, inertia and others), last but not least, public funding must also be mentioned. The number of citations is rather a measure of the financial endowment of the field and not of the "significance" of the journal.

The 206 journals cover well established and thoroughly ploughed fields. Somewhat speciously it could be argued that for correlative, innovative, out-of-the-common and modern topics, which have not had time to accumulate citations and large teams, one must look outside of the 206 .

Michael M. Benarie

Institut National de Recherche

Chimique Appliquée,

91710 Vert le Petit, France

\section{Rapid publication}

SiR,-Rapid publication has become a topic of increasing importance as the camera-ready method and related methods have become more and more popular, especially for papers presented at symposia and the like. The manuscripts must be prepared by the authors according to speoial instructions. In small institutions the authors have to do all the processing themselves in addition to preparing the normal manuscript. They soon find out that a paper of 5-6 pages will take three to four weeks of drawing, photographing, editing, and typing according to the instructions. At a symposium with 200 to 250 papers, I would guess at least 100 will be prepared by the authors. This means that over 7 years are spent by scientists in preparing the cameraready manuscript!

Institutions in developing countries usually tend to be small and have small budgets, and scientists working there are already overloaded with a wide variety of problems inherent in such situations. The preparation of cameraready manuscripts therefore lessens the costly time which could be spent on actual research. Compared to scientists in well-equipped institutions, the scientists in small institutions see their research activities fall increasingly into arrears. I think that for us and other scientists in similar situations the advantages do not always equal the time and misery of preparing a cameraready manuscript. I realise that the advantages for editors as well as for well-equipped scientists are quite substantial.

In case camera-ready manuscripts are required, I would suggest that possibilities for technical assistance are created in this respect for those who do not have it, and for which biologists are certainly not trained.

H. A. M. DE KruiJF

Curacao, Netherlands Antilles
He's repented
The most recent issue of Scientia
Sinica contains the following correc- tion slip: In the aricle "Devote Every Effort to Running Success- fully Socialist Research Institutes of Science" (Sci. Sin., XIX, No. 5), "the arch unrepentant capitalist- roader in the Party Teng Hsiao-ping" should read "Teng Hsiao-ping". 